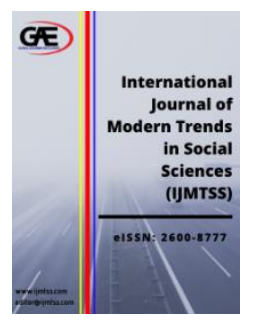

\author{
INTERNATIONAL JOURNAL OF \\ MODERN TRENDS IN \\ SOCIAL SCIENCES \\ (IJMTSS) \\ Www.ijmtss.com
}

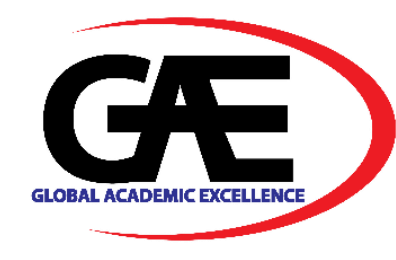

\title{
THE RELATIONSHIP BETWEEN PARENTS' EXPECTATIONS AND MENTAL HEALTH OF HIGH SCHOOL STUDENTS IN HO CHI MINH CITY, VIET NAM
}

\author{
Tuan Pham Van ${ }^{1}$
}

1 Department of Psychology, Faculty of Social Work, University of Labor and Social Affairs (Campus 2), Viet Nam. Email: tuanpv@1dxh.edu.vn

\section{Article Info:}

Article history:

Received date: 14.07.2021

Revised date: 30.07 .2021

Accepted date: 10.08.2021

Published date: 09.09.2021

\section{To cite this document:}

Tuan, P. V. (2021). The Relationship Between Parents' Expectations and Mental Health of High School Students in Ho Chi Minh City, Viet Nam. International Journal of Modern Trends in Social Sciences, 4 (17), 19-27.

DOI: $10.35631 /$ IJMTSS.417003

This work is licensed under CC BY 4.0

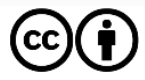

\begin{abstract}
:
Mental health has a great influence on the quality of life and learning outcomes of students. This problem is related to many different factors. It is necessary to clarify the current state of mental health and influencing factors, thereby taking appropriate measures to take care of the mental health of students and help them study effectively. This study examined mental health and parents' expectations on a sample of 242 randomly selected students at a number of high schools in Ho Chi Minh City. Through the DASS42 tool and the scale designed by the research team, the research results showed that the level of parents' expectations for students is not high; the percentage of students with stress is $43.7 \%$, anxiety is $38.6 \%$, depression is $35 \%$, in which the percentage of students with severe and very severe problems are: stress $12.3 \%$, anxiety $10.3 \%$, depression $6.9 \%$, students' mental health problems are closely correlated; Parental expectations are correlated with student mental health problems and are likely to report $12.6 \%$ to $15 \%$ variability in student mental health problems.
\end{abstract}

Keywords:

Mental Health, Parents' Expectations, DASS 42

\section{Introduction}

Mental health plays a very important role, having a great impact on the quality of life and learning outcomes of students in general and high school students in particular (Binh, 2015; Eisenberg, 2017). High school students are a period of strong psycho-physiological development (Hoa, 2008; Dong, 2012), this is a difficult period that requires psycho-social 


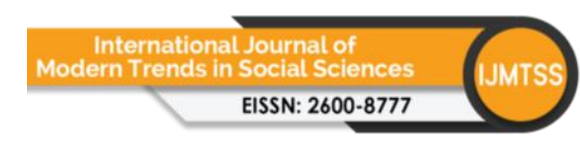

Volume 4 Issue 17 (September 2021) PP. 19-27

DOI 10.35631/IJMTSS.417003

maturity and pressure learning, future orientation, ... These difficulties put children at risk of facing mental health problems (Phuong\&Lam, 2019). Many studies have shown that a large number of students suffer from anxiety disorders (Khanh, 2000; Phuong, 2017), depression (Dat, 2002; Binh\&Mai, 2015; Luong\&Mai, 2019) or stress (Van, 2014; Hang, 2013; Thao, 2018; Phuong\&Lam, 2019); or all three problems: stress, anxiety, depression (Anh et al., 2017; Quynh et al., 2020; Tin et al., 2021). Mental health problems can reduce quality of life, cause difficulties in life, study, and lower student achievement, and can even lead to dropouts or suicide, breaking the law (Eisenberg, 2009; Hoan, 2017; United Nations Children's Fund, 2018). Mental health of students is related to many different subjective and objective factors such as psychophysiological characteristics of age, factors from family and school (Phuong, 2007; Van, 2014; Anh et al. al., 2017). In which, parents' expectations are one of the factors that have a certain influence (Binh \& Mai, 2015; Hoan, 2017; Van, 2020).

Parents' expectations for students, mental health, the relationship between them of students in general and high school students in particular in Ho Chi Minh City has not been studied much, this is an issue that needs further research attention. Our research aims to fill this gap.

\section{Literature Review}

According to the World Health Organization (WHO), mental health is a state of well-being in which the individual realizes his or her own abilities, can cope with the normal stresses of life, can work productively and fruitfully, and is able to make a contribution to his or her community. Adolescents in general and high school students in particular are at high risk for mental health problems, and authors in the world and in Vietnam have been interested in this issue early on, Several studies have been conducted with mixed findings. There are quite a few studies on student stress, especially academic stress. To clarify this issue, different measurement tools have been used, commonly DASS 21 or DASS 42 (Hinkle, 1987; Cormier, 1993; Pigott et al., 1999; Van, 2014; Hang, 2013 ; Thao, 2018; Phuong\&Lam, 2019). Besides stress, anxiety disorder in students is also a matter of concern to many authors such as Khanh (2000), Phuong (2017). In addition to the DASS 21, DASS 42 scales, some authors have used the Zung scale, STAI or diagnostic criteria in DSM-V, ICD 10 to clarify the percentage of students with anxiety disorders. Most studies have found that a large number of high school students have this problem. Some other studies focus on studying student depression through Beck's scale (Carmen, 2007; Bradley, 2011; Dat, 2002; Binh \& Mai, 2015; Luong \& Mai, 2019) or stress (Hang, 2013; Van, 2014; Thao, 2018; Phuong\&Lam, 2019). While some authors are only interested in a specific issue, others are more systematic, these authors simultaneously study stress, anxiety, depression of students and students. indicates that these issues are related (Anh et al., 2017; Quynh et al., 2020; Thai et al., 2020; Tin et al., 2021). The causes leading to mental health problems of high school students have also been analyzed and clarified by many authors. Cassidy (1999), Ender (2010) said that exams, pressure of grades, anxiety about the future, career choices, exam preparation, knowledge volume, family and personal expectations. Phuong (2007), Van (2014), Anh et al., (2017) mention factors such as age-specific psychophysiological characteristics, family and school factors. Binh \& Mai (2015), Hoan (2017), Van (2020) emphasize the expectations of parents, ... Gillispie (2001) said that, in schools and educational institutions, it is necessary to have psychological support for children. Students and facilitators need counseling skills to be able to provide effective support (Anthony, 1993; Egan, 1994). 
Thus, it can be seen that the mental health of high school students has been studied quite a lot, many different research tools on this issue have been used. On the basis of inheriting the research results of previous authors, this study focuses on proving the following points:

1. Parents have quite high expectations for their children.

2. The rate of students having problems with stress, depression and anxiety is quite high. Stress, depression, anxiety of students are correlated with each other.

3. Parents' expectations have a relationship and influence on students' stress, depression, and anxiety.

\section{Methodology}

\section{Sample}

The study was carried out on a sample of 242 high school students randomly selected at 6 high schools in Ho Chi Minh City, including: 104 boys, 138 girls; 85 students in 10th grade, 82 students in 11th grade, 75 students in 12 th grade.

\section{Measures}

The mental health status of students is measured through the DASS-42 scale, which includes 42 items that are specific manifestations of 3 mental health problems: Stress, Anxiety and Depression. Performances are measured through student self-assessment on a scale of 0-3: 0 Doesn't look right to me at all; 1- True to me partly, or sometimes only; 2 - True to me most, or most of the time, is true; 3 - Absolutely true for me, or most of the time true. The DASS-42 scale was developed by scientists at the University of New South Wales (University of New South Wales), Australia and has been standardized and used by many researchers on students and students. Vietnam (Thuan, 2011; Van, 2014; Hang et al., 2019). The analysis results show that the scales have good reliability: Cronbach's Alpha of the Depression scale is 0.90, Cronbach's Alpha of the Stress scale is 0.93; Cronbach's Alpha of the Anxiety scale is 0.87.

Parents' expectations for students are measured through a scale we designed ourselves, a scale of 5 items is the specific expectations of parents for students. Items are measured through student self-assessment with 4 levels: 0 - None; 1 - Occasionally; 2 - Quite often; 3 - Very often. Statistical analysis shows that the scale has a good reliability coefficient, Cronbach's Alpha $=0.86$, no item of the scale has Cronbach's Alpha $<0.60$.

\section{Data Analysis}

The survey results were processed by the statistical software SPSS 20.0. The statistics used include:

Descriptive statistics: calculate mean (M), standard deviation (SD), number (N), percentage (\%) of the scales: parents' expectations, students' mental health, thereby assessing the level of parents' expectations, students' mental health.

For parents' expectations scale, the lowest score is 0 , the highest is 3 , the higher the average score, the greater the expectation.

For the mental health scale. Scores for depression, anxiety and stress are calculated by adding up the scores for the component manifestations, then multiplying by a factor of 2 and are rated on 5 levels: 


\begin{tabular}{lccc} 
Levels & Depression & Anxiety & Stress \\
\hline Normal & $0-9$ & $0-7$ & $0-14$ \\
Light & $10-13$ & $8-9$ & $15-18$ \\
Fit & $14-20$ & $10-14$ & $19-25$ \\
Heavy & $21-27$ & $15-19$ & $26-33$ \\
Very heavy & $\geq 28$ & $\geq 20$ & $\geq 34$
\end{tabular}

Inferential statistics: correlation and regression analysis were used to analyze the relationship between depression, anxiety and stress among students; between parental expectations and student mental health.

\section{Research Results}

Surveying parents' expectations for students, mental health and the relationship between parents' expectations for mental health of high school students in Ho Chi Minh City, we obtained the data below:

Table 1. Parents' Expectations for Students

\begin{tabular}{clccc}
\hline Order & \multicolumn{1}{c}{ Expectations } & M & SD & Rank \\
\hline 1 & $\begin{array}{l}\text { My parents expect me to be more talented than } \\
\text { others }\end{array}$ & 1.38 & 1.06 & 3 \\
2 & $\begin{array}{l}\text { My parents want me to achieve many high } \\
\text { achievements in school }\end{array}$ & 1.51 & 1.04 & 2 \\
3 & $\begin{array}{l}\text { My parents complain and scold me when I get } \\
\text { low grades or when I have flaws }\end{array}$ & 1.19 & 1.09 & 5 \\
4 & $\begin{array}{l}\text { My parents compare me to others, especially } \\
\text { those with good achievements }\end{array}$ & 1.22 & 1.15 & 4 \\
5 & $\begin{array}{l}\text { My parents want me to be their pride } \\
\text { Mean in total: }\end{array}$ & $\mathbf{1 . 4 2}$ & $\mathbf{0 . 8 7}$ & 1
\end{tabular}

* Note: the lowest score is 0, the highest is 3; The higher mean, the higher the parents' expectations. (Source: Survey results of the research team)

The data obtained in Table 1 showed that parents' greatest expectation is to want their children to become their pride $(\mathrm{M}=1.80 / 3.0, \mathrm{SD}=1.08)$, followed by wanting their children to achieve many achievements. high in learning $(\mathrm{M}=1.51 / 3.0, \mathrm{SD}=1.04)$, want him to become a more talented person than others $(\mathrm{M}=1.38 / 3.0, \mathrm{SD}=1.06)$. Lower-level expectations include: comparing your child with others, especially those with good achievements $(\mathrm{M}=1.22 / 3.0, \mathrm{SD}$ $=1.15)$, complaining and scolding when your child gets low marks or when he has flaws $(\mathrm{M}=$ 1.19/3.0, SD = 1.09).

Table 2. Prevalence and Severity of Depression, Anxiety and Stress of Students

\begin{tabular}{lccc}
\hline Levels & $\begin{array}{c}\text { Depression } \\
\mathbf{N}(\boldsymbol{\%})\end{array}$ & $\begin{array}{c}\text { Stress } \\
\mathbf{N}(\boldsymbol{\%})\end{array}$ & $\begin{array}{c}\text { Anxiety } \\
\mathbf{N}(\boldsymbol{\%})\end{array}$ \\
\hline Normal & $158(65.0)$ & $139(57.2)$ & $154(63.4)$ \\
Light & $35(14.4)$ & $20(8.2)$ & $41(16.9)$ \\
Fit & $32(13.2)$ & $54(22.2)$ & $22(9.1)$ \\
Heavy & $13(5.3)$ & $17(7.0)$ & $13(5.4)$ \\
Very heavy & $4(1.6)$ & $13(5.3)$ & $12(4.9)$ \\
\multicolumn{1}{c}{ Total: } & $\mathbf{2 4 2}$ & $\mathbf{2 4 2}$ & $\mathbf{2 4 2}$
\end{tabular}


(Source: Survey results of the research team)

The survey results in Table 2 showed that:

- About depression: $35 \%$ have depression of varying degrees: $14.4 \%$ mild, $13.2 \%$ moderate, $5.3 \%$ severe, $1.6 \%$ very severe.

- About stress: $43.7 \%$ had different levels of stress: $8.2 \%$ was mild, $22.2 \%$ was moderate, $7.0 \%$ was severe, $5.3 \%$ was very severe.

- About anxiety: $38.6 \%$ have different degrees of anxiety: $16.9 \%$ mild, $9.1 \%$ moderate, $5.4 \%$ severe, $4.9 \%$ very severe.

Table 3. Relationship Between Depression, Anxiety and Stress in Students

\begin{tabular}{lccc}
\hline & Depression & Anxiety & Stress \\
\cline { 2 - 4 } Depression & 1 & & \\
Anxiety & $.71^{*}$ & 1 & 1 \\
Stress & $.73^{*}$ & $.78^{*}$ & \\
& & & \\
* Note: * với $p<0.05$ & & &
\end{tabular}

The results of analysis in Table 3 showed that students' depression, anxiety and stress are positively correlated: the correlation coefficient $(\mathrm{r})$ between depression and anxiety is 0.71 $(\mathrm{p}<0.05)$, the correlation coefficient is $0.71(\mathrm{p}<0.05)$. The correlation between depression and stress was $0.73(\mathrm{p}<0.05)$, the correlation coefficient between stress and anxiety was 0.78 $(\mathrm{p}<0.05)$.

Table 4. Relationship Between Parents' Expectations and Depression, Anxiety and Stress of Students

\section{Depression \\ Anxiety \\ Stress}

\begin{tabular}{cc}
$\mathbf{r}$ & $\mathbf{R}^{\mathbf{2}}$ \\
\hline $0.39^{*}$ & $0.150^{* *}$ \\
$0.36^{*}$ & $0.126^{* *}$ \\
$0.38^{*}$ & $0.146^{* *}$
\end{tabular}

* Note: * với $\mathrm{p}<0.05, * *$ với $\mathrm{p}<0.001$

(Source: Survey results of the research team)

The analysis data in Table 4 showed that parents' expectations for students in the sample are positively correlated with all three mental health problems of students: correlation coefficient (r) between expectations of Parents with depression problems was $0.39(\mathrm{p}<0.05)$, with anxiety problems $0.36(\mathrm{p}<0.05)$, with stress problems $0.38(\mathrm{p}<0.05)$.

Research results in Table 4 also showed that parents' expectations for students in the sample are able to predict between $12.6 \%$ and $15 \%$ of the change in mental health problems of students. specifically: the ability to report a change of anxiety is $12.6 \%$, of stress is $14.6 \%$, of depression is $15 \%$. 


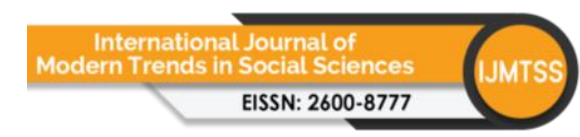

Volume 4 Issue 17 (September 2021) PP. 19-27

DOI 10.35631/IJMTSS.417003

\section{Discussion}

The data in Table 1 showed that parents of students in the sample have expectations about their children, but at a low level, most of the expectations are low (table 1). This finding of ours is much different from the results of some authors, Tuan's study (2014) showed that parents' expectations on their children are very high. The results of our research showed that students do not currently face great pressure from parents. This is a positive signal, having this result is because a part of parents is aware of not expecting too much from their children because this can put pressure on them, negatively affect to their mental health and the quality of their learning and life; It may also be because a part of parents are not really interested in their children's learning, development, etc.

The study also showed that high school students in Ho Chi Minh City are currently experiencing various mental health problems (table 2). The number of students with mental health problems such as stress, anxiety, depression at different levels is quite high $(43.7 \%$, $38.6 \%$, 35\% respectively), in which the number of students significant and very severe problems (stress: $12.3 \%$, anxiety: $10.3 \%$, depression: $6.9 \%$ ). This is a number worth paying attention to. The results of our study have certain differences with the research results of the authors in the world and in Vietnam, but not much: Research by Bradley et al. (2011) indicated that the rate of depression among 18-year-olds is about 20-25\%, according to Ryan (2005) this figure is $30 \%$. A study by the Vietnam Institute of Psychology in 2000 found that $22.5 \%$ of students showed signs of anxiety and depression (Dat, 2003). Research by Anh et al. (2017) concluded that high school students have different levels of mental health problems: mild stress is $37.8 \%$, moderate is $43.2 \%$, severe is $17.6 \%$, very severe $1.4 \%$. Mild anxiety was $22.6 \%$, moderate was $50.5 \%$, severe was $16.1 \%$ and very severe was $10.8 \%$. Mild depression is $53.7 \%$, moderate depression is $14.8 \%$, severe is $25.9 \%$, very severe is $5.6 \%$. Phuong (2019) studied on anxiety in high school students through the Zung scale found that $13.14 \%$ of students suffered from anxiety disorders, specifically $7.72 \%$ mild anxiety, $4.49 \%$ moderate anxiety and $0.9 \%$ pathological anxiety. Luong \& Mai (2019) research on depression in high school students showed that about $20 \%$ of students have some degree of depression. Among the students with depression, most of them are mildly depressed, the rate of major depression is only about $1 \%$ of the total study population. Quynh et al. (2020) research on depression and anxiety on 497 students through the DASS-21 tool, found that students showed signs of depression at $38.2 \%$, anxiety was $39.2 \%$. Research by Tin et al. (2021) on the prevalence of stress, anxiety and depression disorders among students, they came to the conclusion that the rate of stress in students is $52.1 \%$, the rate of anxiety is $63.8 \%$ and the rate of depression is 42 , first $\%$. In which, the moderate level of all three disorders is quite high, ranging from $20.3 \%$ to $31.2 \%$. The rate of very severe severity of stress disorder and depression was lowest at $0.4 \%$ and $1.1 \%$. Meanwhile, the severity of anxiety disorder is quite high at $10.6 \%$. In particular, our research results have many similarities with the results of some studies on mental health of high school students in Ho Chi Minh City: the study of Truc et al. (2020) showed that there are more than $35 \%$ stressed, nearly $60 \%$ anxiety and nearly $39 \%$ depression at various levels. Thai et al. (2020) found that the rates of stress, depression and anxiety disorders among students were $36.1 \%, 39.8 \%$ and $59.8 \%$, respectively.

In our study, mental health problems (stress, anxiety, depression) of high school students in Ho Chi Minh City were found to be positively correlated with each other quite closely $(\mathrm{r}=0.71$ $0.78, \mathrm{p}<0.05$, table 3 ). This means that when a student's mental health problem increases or decreases, another problem increases or decreases. This result shows that it is necessary to pay attention to comprehensive mental health care for students.

Copyright (C) GLOBAL ACADEMIC EXCELLENCE (M) SDN BHD - All rights reserved 
Parental expectations were correlated with students' mental health problems, but not significantly (table 4). From this result, we believe that parents' expectations are not the main cause of students' mental health problems but also one of the influencing factors. Further studies are needed to clarify the main causes of student mental health problems.

\section{Conclusion}

The research results showed that the arguments in our 3 arguments, 2 and 3 are correct. High school students in Ho Chi Minh City currently have mental health problems: Stress, Depression and Anxiety. The proportion of students with severe and very severe mental health problems is relatively high (Stress is $12.3 \%$, Anxiety is $10.3 \%$, Depression is 6.9\%). Students' mental health problems are positively correlated. Parents' expectations are positively correlated and have a certain influence on the mental health of students. These results show the need to care and support students to deal with mental health issues. To protect students from mental health problems, teachers and high schools in Ho Chi Minh City need to advise parents on knowledge about mental health care for students, especially the group of senior students; it is necessary to equip students with life skills, knowledge and self-care skills for mental health; care and early detection of students with mental health problems; effectively organize psychological counseling activities for students in schools; organize favorable learning environment and conditions for students.

\section{References}

Anthony Y. (1993). Counseling - a problem solving approach. Amour, Publishing.

Anh, L.T.T., Hai, N.T., Duc, N.Q., \& Xanh, P.T. (2017). Stress, anxiety, depression and some related factors in high school students in $\mathrm{Phu} \mathrm{Cu}$ - Phu $\mathrm{Cu}$ district - Hung Yen province in the 2016-2017 school year. Journal of Preventive Medicine, 27(10).

Ai, N.T.N., Hoan, T.T. (2014). The relationship between parental expectations and psychological stress levels of high school students. Proceedings of the national scientific conference: Mental health in schools, Dong Nai.

Bradley, T.E., Breann, M.E., Gina, L., Janet, W., Hallie, S., Emily, W., Meredith, H., Jenna, D., Janet, S.M., \& Elizabeth, P. (2011). Counseling outcomes from 1990 to 2008 for school-age youth with depression: A meta-analysis. Journal of Counseling and Development, 89, 439-457.

Carmen R. Wilson VanVoorhis - Tracie L. Blumentritt (2007). Psychometric Properties of the Beck Depression Inventory-II in a ClinicallyIdentified Sample of Mexican American Adolescents. Journal Child Fam Study, 16, 789-798.

Binh, P.T., \& Mai, P.D. (2015). Depression in today's adolescents. Proceedings of the international scientific conference: Psychology and education in the cause of human development in Vietnam. Pedagogical University Publishing House, Ha Noi.

Cassidy T. (1999). Stress. Cognition and health, Routledge, London.

Cormier L.S - Hackney, H. (1993). The professional counselor: a process guide to helping (2nd ed.). Needham heights, ma: allyn and bacon.

Dat, N.B. (2002). Diagnosis of depressive disorder in high school students in Hanoi. Master thesis in Psychology, Hanoi University of Social Sciences and Humanities.

Dat, N.B. (2003). Diagnostic results of depression in high school students in Hanoi. Journal of Psychology, 7, 57-63.

Dong, N.V. (2012). Developmental psychology. National Political Publishing House.

Ender S. C and Newton, F. B (2010). Students helping students: a guide for peer educators on college campuses. San Francisco: jossey-bass. 
Egan G. (1994). The skilled helper: a problemmanagement approach to helping. Brooks/cole publishing company: pacific grove, California

Eisenberg, D., Gollust, S. E., Golberstein, E., \& Hefner, J. L. (2007). Prevalence and correlates of depression, anxiety, and suicidality among university students. American Journal of Orthopsychiatry, 77(4), 534-542.

Eisenberg, D., Downs, M., \& Golberstein, S. (2009). Stigma and help-seeking for mental health among college students. Medical Care Research and Review, 66(5), 522-541.

Gillispie, B. (2001). History of academic advising. A chronology of academic advising in america.

Hinkle L.E. (1987). Stress and disease. The concept after 50 years, science, medicine and man, $25,561-566$.

Hang, D.T.L. (2013). Stress of high school students. Thesis of Doctorate in Psychology. Academy of Social Sciences - Vietnam Academy of Social Sciences.

Hang, N.T., Oanh, V.T.H., Thom, C.T., \& Hieu, B.T. (2019). Syrvey on anxiety disorder among $4^{\text {th }}$ year students at Nam Dinh university of Nursing. Nursing Science, 2(2), 8388.

Hoa, D.T.D. (2008). Curriculum Developmental Psychology. Pedagogical University Publishing House, Ha Noi.

Hoan, T.T. (2017). Association between meeting parental expectations and quality of life of high school students. Proceedings of the first international conference on Psychology in Southeast Asia: Human happiness and sustainable development. Hanoi National University Publishing House.

Khanh, N.C. (2000). Counseling and psychotherapy for children with behavioral disorders and school difficulties. Vietnamese - French Conference on Psychology, Hanoi.

Luong, T.T.M., \& Mai, P.D. (2019). Situation of depression in high school students: a study in Ninh Binh province and Hanoi city. Journal of Education, 166, 146-150.

Mai, P.T. (2020). Depression in high school students. Doctoral Thesis in Psychology, Hanoi National University of Education, Hanoi.

Pigott, T.A. (1999). Gender differences in the epidemiology and treatment of anxiety disorders. Journal of clinical psychiatry, 60(18), 4-15.

Phuong, N.T.H., \& Lam, D.X. (2019). The reality of academic stress of 12th grade students in Da Nang city. Journal of Education, 2, 121-127.

Phuong, N.T.H. (2007). Research on the causes of anxiety disorders in high school students. Master thesis in Psychology, Hanoi University of Social Sciences and Humanities.

Quynh, T.T. ., Anh, T.., Dinh, N.V., \& Van, L.T.T. (2020). Current situation of depression, anxiety and some related factors among pupils of a high school in Nghe An province in 2019-2022. Journal of Preventive Medicine, 30(6), 83.

Thai, T.T., Vu, T.L.L.N., Bui, T.H.H. (2020). Mental Health Literacy and Help-Seeking Preferences in High School Students in Ho Chi Minh City, Vietnam. School Mental Health, 12(2), 378-387.

Thao, N.T.P., Tho, N.T.T., Chi, N.T.Q., Cam, N.N., \& Lam, N.T. (2018). Stress situation of students at Dinh Tien Hoang High School, Ba Dinh, Hanoi. Journal of Preventive medicine, 28(4), 20-28.

Thuan, L.M. (2011). Psychological well-being of students: A cross-sectional study. Journal of Practice Medicine, 774(7), 72-75.

Tin, D.T., Thuan, L.M, \& Thanh, H.N. (2021). Stress, anxiety, depression, and realated factors among students at Vi Thanh high school for the gifted in Hau Giang province. Ho Chi Minh City Journal of Medicine, 5(2), 161 - 167. 
Tuan, B.D. (2014). Parents' expectations of their children's success. Proceedings of the scientific conference: Situation and solutions to prevent school violence in high schools. Ho Chi Minh City University of Education.

United Nations Children's Fund. (2018). Mental health and psychosocial well-being of children and young people in some provinces and cities in Vietnam. UNICEF, 25-113.

Van, T.T.H. (2014). Stress situation of high school students and some related factors at Phan Dinh Phung High School, Hanoi in 2014. University of Public Health.

Van, N.T. (2020). Factors affecting school anxiety disorder of high school students in Ho Chi Minh City. Journal of Education Management Science, 1(25), 111-118.

World Health Organization. Promoting mental health: concepts, emerging evidence, practice (Summary Report) Geneva: World Health Organization; 2004. 